\title{
Standing Situations and Issues of Open Source Policy in East Asian Nations: Outcomes of Open Source Research Workshop of East Asia
}

\author{
Tetsuo Noda ${ }^{1}$, Terutaka Tansho ${ }^{1}$, and Shane Coughlan ${ }^{2}$ \\ ${ }^{1}$ Shimane University \\ nodatesoc.shimane-u.ac.jp \\ tansho@riko.shimane-u.ac.jp \\ ${ }^{2}$ Regional Director Asia of Open Invention Network \\ shane@opendawn.com
}

\begin{abstract}
East Asia nations have made some progress with this technology, and started to introduce OSS for e-government systems during the early part of this century. Many countries granted it a central role in their policies. The reasons for this include adoption of software based on standard specification, liberation from vender lock-in, or opposition to the market control of proprietary software. However, the primary reason is to reduce adoption costs for e-government systems. While this policy work is useful, there is a great deal more that needs to be done. The OSS adoption policy in each nation of East Asia must be accompanied by technological progress in domestic IT service industries or US multinationals will expand at the cost of local businesses. If this continues unchecked it will create a new form of lock-in for East Asian nations. Some Asian nations are trying to promote their domestic IT service industries, putting their OSS adoption policy to practical use, and this workshop will provide case studies of that work. It will also provide a forum for discussing current challenges and opportunities around both policy and practical implementation issues across Asia.
\end{abstract}

\section{Introduction}

As part of Shimane University's research into Open Source matters, the Research Project Promotion Institute ${ }^{1}$ has run a project called 'Stabilization and Business Models for Open Source Software' since 2008. One deliverable has been the hosting of a seminar entitled 'Open Source Research Workshop in East Asia' on November 26th and 27th 2010. This seminar was attended by Japanese and academic thoughtleaders as well as a diverse range of international participants.

East Asian nations have made some progress with Open Source technology in the last decade, building on the early introduction of OSS for e-Government systems at

${ }^{1}$ Shimane University is executing forward empirical and theoretical research on the productivity of the business model's construction is to be done by the cooperation of the industrialgovernment-academic-community complex.

http://albatross.soc.shimane-u.ac.jp/oss/index.html 
the turn of the last century. Many countries granted OSS a central role in their policies for reasons like adherence to standard specification, freedom from vender lock-in, or opposition to the market control of proprietary software. However, the primary reason is to reduce adoption costs for e-Government systems.

While the initial governmental policy work has been useful, a great deal more needs to be done before the value proposition offered by OSS is realized. One key example is that the OSS adoption policy in each nation of East Asia must be accompanied by progress in domestic IT service industries to prevent multinationals expanding at the cost of local businesses. This is a consideration given that Open Source originates from the West coast of the USA and is still primarily developed and enhanced by US corporations. It could even be said that the current technical evolution of OSS is driven mainly by companies originating from the United States. While the inherent benefits of OSS extend beyond the boundaries of enterprises, organizations and nations, and OSS has the potential to foster new business markets in regions other than North America, the current status quo has the potential for a new form of lock-in for East Asian nations.

Some East Asian nations are trying to promote domestic IT service industries by putting their OSS adoption policy to practical use, and this workshop provided case studies of that work. It also provided a forum for discussing current challenges and opportunities around both policy and practical implementation issues across East Asian nations.

The intention was to extract the aspects of Open Source adoption policy that are not accompanied by the technological progress in domestic IT service industries, and from this derive an indication of the role government should play in East Asia and in other developing countries generally.

At the workshop Open Source thought-leaders from Japan, China, South Korea, Vietnam, The Gambia and Ireland discussed the nuances and known outcomes of Open Source adoption policies, and contributed to the publication of a proceeding as a special issue of our bulletin ${ }^{2}$ in conjunction with the event. As the contentions of the researchers are contained in the proceeding, the focus of this paper is to explain the presentations of the researchers and the main points of discussion at the workshop.

\section{Open Source Policy in East Asian Nations}

\subsection{Open Source Policy in Japan}

Mr. Shunichi Tashiro, the chief officer of Open Software Center at the Japanese Industrial-Technology Promotion Agency ${ }^{3}$, introduced Open Source Policy in Japan and the activity of his department.

\footnotetext{
2 Journal of Economics Memoirs Of The Faculty Of Law And Literature, Shimane University No.37 Special Issue "Open Source Policy and Promotion of IT Industries in East Asia" Nov.2010.

3 The Open Software Center is an organization within the Information-Technology Promotion Agency (IPA), Japan, one of Independent Administrative Agencies 1 in Japan, and is operated under the budget of the Japanese government. http://www.ipa.go.jp/index-e.html
} 
He explained that software is built on platforms, and that it ultimately cannot work without interoperability with other software. Openness of the platforms and interfaces are crucial to provide freedom to software developers and users, and therefore to foster a healthy, competitive environment in the national and international software industry. The Open Software Center was founded in 2006 to promote Open Source software and open standards as an important aspect of information services, development methods, assessment criteria, standardization systems, and research studies. The core proposition is that OSS enhances knowledge sharing and sustains a collaborative development environment.

The key issue is probably 'Open Standards' rather than Open Source. Open Standards are technical standards for which specifications are publicly available, that any part can use and that any party can participate in regarding further development. These are critical to ensure the interoperability of software and freedom of action for software developers and users.

One example of practical engagement with this issue in Japan is the standardization of the programming language Ruby, which is now in the screening process of JIS (Japanese Industrial Standards) and will soon obtain JIS certification before submission to ISO (International Organization for Standardization) in 2011. This will encourage the Japanese-created Ruby language to be adopted in e-Government systems and enterprise environments across the world.

In this way a Japanese government agency is supporting the promotion of the domestic information service industry while also contributing positively to the global IT market.

\subsection{Open Source and the Software Industry in China}

Dr. Dongbin Wang, the researcher of Center of China Study, Tsinghua University ${ }^{4}$, introduced the history of the Internet and Open Source in China.

Before China joined in WTO in 2001, software piracy was very popular and lead to a large loss of potential revenue every year for the industry. One high profile example is that Microsoft's software products were frequently copied and illegally installed on computers across the private and public sectors, a situation that somewhat ironically also helped Microsoft become the de-facto norm in computing for the local market. However, after 2001 the Chinese government began to increase the legislation and enforcement around software piracy, and companies like Microsoft accompanied this shift in the local market norms by taking a much stricter line regarding unauthorized coping of their products. One side effect of this was for many cyber cafes to react by switching to Linux and other Open Source software to reduce licensing costs.

It is possible to conclude that intellectual property rights protection is a doubleedged sword for Open Source development and adoption. Recently many large companies in China have formally preferred Linux as a pre-installation operation system, but due to the rampant piracy of Windows in the past there is an on-going

${ }^{4}$ Center for China Study (CCS), Tsinghua University is a leading academic think-tank for policy making in China. Its researches cover most fields of China Studies, which include Development and China Study, Chinese Economy and Development Strategy. http://www.facebook.com/group.php?gid=48859734768 
familiarity and desire for Microsoft and other proprietary products. In effect, the over commercialization and effective commoditization of proprietary software presents a key obstacle to Open Source expansion in China.

\subsection{Open Source Software - Education, Practice and Applications at the University of Engineering and Technology}

Dr. Nam Hai Nguyen \& Dr. Quang Hieu Le from the University of Engineering and Technology school of the Vietnam National University, Hanoi(UET) ${ }^{5}$ provided information on policies and challenges experienced by the Vietnamese government regarding OSS development in their country.

The national government has long emphasized a focus on and priority for OSS development and deployment. For example, in 2006 the government mandated that procurement of IT products and services should give preference to investment, adoption and application of OSS and OSS-based software products, especially those with quality and functionality equal to proprietary software supplied by domestic enterprises

UET has engaged with the trend towards OSS by exploring best practices in the field and building educational knowledge to share with students and with society-atlarge. Through these activities the faculty members of UET play an important role in advancing the widespread use of OSS in teaching and research activities, and in practical deployment outside of the confines of academia.

To further both the activities of UET, and the Vietnamese engagement with OSS generally, efficient international cooperation is of crucial importance. UET is a leading proponent of such cooperation, is seeking to build knowledge-sharing bridges with the broader global community.

\section{Free and Open Source Software Governance: Turning Potential into Deliverables}

The presentation examined some of the key governance approaches and resources that help turn the potential of FOSS into a deliverable, whether that deliverable is a product, revenue stream or altruistic solution to a shared problem.

The concept of governance has become increasingly important because - while Free and Open Source Software (FOSS) offers tremendous potential to create technology platforms and develop business opportunities - the best methods to obtain results from FOSS adoption have not always been clear. Simply being 'open' or using third party code appears to have limited value on its own, and does not address the management requirements or legal imperatives that stakeholders face. Deriving ongoing value from FOSS requires understanding the ideas and norms that underpin the field. FOSS has a premise that third-party sharing and contribution delivers enhanced value over proprietary approaches to managing software, and that FOSS can deliver this value through copyright licenses that allow everyone to use, study, share and improve software code. As this idea has reached the mainstream, the licenses are increasingly the

\footnotetext{
${ }^{5}$ http://www.vnu.edu.vn/en/contents/index.php?ID=932
} 
subject of legal and management scrutiny, and best practices have inevitably emerged for adopting, developing and deploying code subject to their terms.

It was explained how organizations ranging from the Linux Foundation to Free Software Foundation Europe have built networks, encouraged publications and developed tools to assist their own audiences and the broader community of all potential FOSS stakeholders, and some of these governance projects or organizations were explored in brief case studies.

\section{Discussion and Conclusion: The Potential Crowding-Out Effect of Government Policy}

The majority of the presentations therefore engaged with the role of each Asian government or educational institutional in furthering Open Source policy and its practical application. One immediately observable point from their exploration is that each nation discussed places importance on Open Source adoption and supports it politically.

However, the point was raised that excessive policy engagement by central government might spoil the development of Open Source communities by creating a crowding-out effect. There are many stakeholders involved and the interests of these stakeholders are not necessarily entirely in sync. The development methods of Open Source software often include collaboration on the Internet through the participation of a number of developers, corporations and other stakeholders. This environment is competitive not only towards proprietary software but also within itself, and as such requires the flexibility that markets and their associated competitiveness provide.

As the motivation factors of Open Source software developers and investors vary, they tend to participate in creating code and therefore platforms with broadly applicable value. Government engagement needs to take this into account, and avoid causing the risk of constrained, prescriptive environments for Open Source development. This applies in the educational field too. While it is clearly important to explore and integrate OSS in educational environments, especially in the context of computer engineering, such coverage needs to be broad. The field needs to be presented in a context that does not ignore the way that OSS often appears, grows and delivers value outside of the traditional constraints and assumptions of formal engineering education. The discussion suggested that governmental policy around OSS is not clear cut. While positive policy is to be encouraged, the value offered by OSS needs to be understood clearly to ensure it is not inadvertently smothered by well-meaning but ineffective mandates. This indicates that perhaps there are 'new' issues of Open Source adoption policy in East Asian nations to consider, and all participants at the workshop agreed to proceed with examination of how these issues can be resolved in a future workshop.

\section{References}

1. Noda, T., Tansho, T.: Regional Industrial Promotion through Open Source Software by Local Government in Japan. In: Proceeding of the First International Workshop on Building Sustainable Open Source Communities (2009) 
2. Noda, T., Tansho, T.: Open Source Introduction Policy and Promotion of Regional Industries in Japan: Open Source Software. In: Ågerfalk, P., Boldyreff, C., GonzálezBarahona, J.M., Madey, G.R., Noll, J. (eds.) OSS 2010. IFIP AICT, vol. 319, pp. 425-426. Springer, Heidelberg (2010)

3. Wang, D.: Open Source and Software Industry in China. Journal of Economics Memoirs of the Faculty of Law and Literature (November 2010); Shimane University No.37 Special Issue, Open Source Policy and Promotion of IT Industries in East Asia

4. Yi, S., Noda, T., Oh, J.: Comparative study on the implementation and performance of open source activating policy between Korea and Japan. National Information Agency Society, Korea (2009)

5. Yi, S., Noda, T.: Enhancing the Circulation: Some Implications on the OSS Policy and IT Industry Promotion. Journal of Economics Memoirs of the Faculty of Law And Literature (November 2010); Shimane University No.37 Special Issue Open Source Policy and Promotion of IT Industries in East Asia 